\title{
Clinical outcome, healthcare cost and length of hospital stay among patients with bloodstream infections and acute leukemia in a cancer center in Eastern India
}

\author{
Chelsea Elizabeth Muennichow ${ }^{1, a}$, Gaurav Goel MD, DNB, MNAMS², Arpita Bhattacharyya FRCP ${ }^{3}$, Reena Nair MD ${ }^{4}$, \\ Mammen Chandy MD, FRACP, FRCPA, FRCP ${ }^{4}$ and Sanjay Bhattacharya MD, DNB, FRCPath ${ }^{2}$ \\ ${ }^{1}$ Department of Molecular and Cell Biology, Neurobiology, University of California at Berkeley, Berkeley, California, ${ }^{2}$ Department of Microbiology, Tata Medical \\ Center, Kolkata, India, ${ }^{3}$ Department of Pediatric Oncology, Tata Medical Center, Kolkata, India and ${ }^{4}$ Department of Clinical Hematology, Tata Medical Center, \\ Kolkata, India
}

To the Editor-Acute leukemia is one of the most common forms of malignancy reported globally. Patients with acute leukemia acquire infections for many reasons related to disease, chemotherapy, immunosuppression, the use of vascular access devices, and mucosal barrier injury. Bloodstream infections (BSIs) are potentially the most serious infections in leukemic patients; they often lead to morbidity, hospitalization, and sometimes death. In a previous study, we reported the impact of BSI as a predictor of length of hospital stay (LOS) and cost of care in patients with cancer. ${ }^{1}$ In this study, conducted from April 2015 to March 2016, we investigated the effect of BSI on LOS, mortality rates, and healthcare cost among patients with acute leukemia. In total, 350 patients were analyzed during the study period: 234 acute lymphoblastic leukemia (ALL) patients (median age, 8 years; range, 1.5-68.6 years; male:female ratio, 1.8:1) and 116 acute myeloblastic leukemia (AML) patients (median age: 32 years; range, 2.8-71.1 years; male:female ratio, 1:1).

Among patients with gram-positive bacterial BSIs only 1 methicillin-resistant Staphylococcus aureus (MRSA) BSI was detected, and 5 methicillin-sensitive $S$. aureus BSIs were detected. Among gram-negative bacillary BSIs, carbapenem resistance varied from $22 \%$ to $81 \%$. This resistance was greatest among Klebsiella spp, but it was also observed in Escherichia coli, Pseudomonas aeruginosa, and Acinetobacter spp. We detected 2 cases of colistin-resistant Klebsiella. Surveillance cultures from stool samples showed carbapenem resistance in gram-negative bacilli in 59\% of patients, and surveillance cultures from throat swabs showed carbapenem resistance in gram negative bacilli in $18 \%$ of patients.

Gram-negative bacterial BSIs were the most common, followed by BSIs due to gram-positive cocci and Candida parapsilosis (Table 1). The median duration of hospital stay for patients with a BSI was highest for those with Candida BSIs (32 days) followed by those with gram-positive bacterial BSIs (25 days) and those with gram-negative bacterial BSIs (22 days). The intensive care unit (ICU) admission rate was highest for patients with gram-negative bacterial BSIs (23 of $69,33.3 \%$ ) followed by those with grampositive bacterial BSIs ( 8 of $43,18.6 \%$ ). The ICU admission rate was least for Candida cases in this study (0 or 2, $0 \%)$. The 30 -day all-

Author for correspondence: Dr Sanjay Bhattacharya, MD, DNB, FRCPath, Tata Medical Center, 14 Major Arterial Road (E-W), Newtown, Kolkata 700160, India. E-mail: drsanjay1970@hotmail.com

${ }^{a}$ Tata Social Intern student.

Cite this article: Muennichow CE, et al. (2018). Clinical Outcome, Healthcare Cost and Length of Hospital Stay Among Patients With Bloodstream Infections and Acute Leukemia in a Cancer Center in Eastern India. Infection Control \& Hospital Epidemiology 2018, 39, 1013-1014. doi: 10.1017/ice.2018.118 cause mortality and BSI-related attributable mortality rate was highest for gram-negative bacterial BSI patients (20.3\%).

The clinical outcome data of the present study assume significance in view of the high prevalence of multidrug-resistant (MDR) gram-negative bacterial infections in this setting. ${ }^{2,3} \mathrm{We}$ have previously reported cases from our center of colistinresistant Klebsiella among both pediatric and adult patients. ${ }^{4,5}$ In the period between 2014 and 2015, we reported 30-day all-cause mortality among patients with carbapenem-resistant E. coli $(0 \%)$, Klebsiella pneumoniae (40\%), P. aeruginosa (50\%), and Acinetobacter baumannii (60\%). ${ }^{6}$

In the current study, the average cost for hospital stay was highest for patients with Candida BSIs (US\$12,232 [Rs. 795,134]), followed by those with gram-negative bacterial BSIs (US $\$ 4,945$ [Rs. 321,433]). The average cost for hospital stay was lowest for those with gram-positive bacterial BSIs (US $\$ 4,163$ [Rs. $270,607]$ ). In our previous study, among all cancer patients (and not restricted to those with BSIs), we found that the overall mean LOS was 5.9 days, the average cost of care per admission was US $\$ 1,413$ (Rs. 95,208), and the all-cause mortality rate was $5.7 \%{ }^{1}$

The comparison of healthcare outcome measures helps us to understand the efficacy of various clinical interventions, such as chemotherapy regimens and infection prevention and control measures, as well as the effect of infrastructure development or resource allocation. Data on these measures are far less commonly available from low- or middle-income countries than from developed economies, but they are important globally because of the migration of people for work, exigencies or medical tourism. A study from the United States showed that for patients with neutropenia plus infection, the mean hospitalization costs were $\$ 27,587$, the LOS was 12.6 days, and the mortality rate was $19.4 \%{ }^{7}$ In a study from Mexico, the mean cost per hospital stay was US\$2,246 among patients with ALL. ${ }^{8}$ An Indian study on patients undergoing cardiothoracic surgery, patients with hospital-acquired bacteremia experienced a significantly longer total hospital stay (mean, 22.9 days), longer ICU stay (mean, 11.3 days), a higher mortality rate (mean, 54\%), and higher cost (mean, US\$14,818) than similar patients without bacteremia. ${ }^{9}$

Healthcare service providers must take appropriate measures to mitigate the negative effect of infections on clinical and health economic outcome measures. One of the key interventions to achieve a positive change is an awareness, education, and training program for care providers regarding matters related to infection epidemiology, diagnosis, and appropriate management. An Indian study from a tertiary-care teaching hospital reported that for every dollar spent on training, the return of investment was $\$ 236$ in avoidance of healthcare-associated infections (HAIs). ${ }^{10}$ 
Table 1. Patient Profiles: Bloodstream Infections, Length of Hospital Stay, and Hospital Cost from April 2015 to March 2016

\begin{tabular}{|c|c|c|c|c|c|c|c|c|}
\hline Cause of BSI & $\begin{array}{l}\text { No. of } \\
\text { BSIs }\end{array}$ & $\begin{array}{l}\text { No. of } \\
\text { Patients }\end{array}$ & $\begin{array}{l}\text { Neutrophil Count } \\
\text { During BSI, median } \\
\text { cells/ } \mu \mathrm{L} \text { (range) }\end{array}$ & $\begin{array}{l}\text { LOS, } \\
\text { median d } \\
\text { (range) }\end{array}$ & $\begin{array}{c}\text { ICU Admission, } \\
\text { no./total }(\%)\end{array}$ & $\begin{array}{c}\text { All-Cause (Crude) } \\
\text { Mortality at Day } 30 \\
\text { from BSI, no./total (\%) }\end{array}$ & $\begin{array}{c}\text { Attributable Mortality } \\
\text { at Day } 30 \text { from BSI, } \\
\text { no./total (\%) }\end{array}$ & $\begin{array}{l}\text { Total Hospital Bill During } \\
\text { the Admission Episode, } \\
\text { median cost (range) }\end{array}$ \\
\hline $\begin{array}{l}\text { Gram-negative } \\
\text { bacilli }\end{array}$ & 113 & 69 & $33(0-50,730)$ & $22(3-55)$ & $23 / 69(33.3)$ & $14 / 69(20.3)$ & $11 / 69$ (15.9) & $\begin{array}{c}\text { US\$4,945 }(267-62,910) \\
\text { Rs. } 321,433(17,358- \\
408,918)\end{array}$ \\
\hline $\begin{array}{l}\text { Gram-positive } \\
\text { cocci }\end{array}$ & 53 & 43 & $136(4-23,700)$ & $23(5-47)$ & $8 / 43(18.6)$ & $7 / 43$ (16.3) & $1 / 43(2.3)$ & $\begin{array}{c}\text { US\$4,163 }(367-42,317) \\
\text { Rs. } 270,607(23,870- \\
2,750,653)\end{array}$ \\
\hline Candida spp & 2 & 2 & $220(30-410)$ & $32(12-51)$ & $0 / 2(0)$ & $0(0)$ & $0 / 2(0)$ & $\begin{array}{c}\text { US\$12,232 }(4,116-20,349) \\
\text { Rs. } 795,134(267,560- \\
1,322,708)\end{array}$ \\
\hline
\end{tabular}

NOTE. BSI, bloodstream infection; LOS, length of hospital stay; ICU, intensive care unit; Rs, rupees.

The infection prevention and control measures introduced in our hospital to mitigate the problem of infection in patients with acute leukemia have included numerous interventions: (1) surveillance culture for detection of MDR bacteria in stool samples and throat swabs, (2) use of direct susceptibility tests on positive blood cultures for early detection of resistant organisms, (3) use of polymerase chain reaction-based rapid detection of carbapenemresistant genes, (4) early empirical therapy with polymyxin based treatment regimens in those previously infected or colonized with carbapenem-resistant multidrug-resistant gram-negative bacteria (MDR-GNB), and (5) accreditation of our infection control systems (NABH Safe I: National Accreditation Board for Hospitals and Healthcare providers). Cost of health care, length of hospital stay, and deaths from infections are affected by many factors, such as human resources, technology, clinical care strategies, which we wish to explore in future controlled studies.

Acknowledgments. We would like to thank the Tata Medical Center Trust, India, for supporting the Tata Social Internship program.

Financial support. No external financial support was provided relevant to this article.

Potential conflicts of interest. All authors report no conflicts of interest relevant to this article.

\section{References}

1. Devereux S, Goel G, Sengupta K, Bhattacharya S. Bloodstream infections as a predictor of length of hospital stay and cost of care in patients with cancer. J Acad Clin Microbiol 2017;19:118-120.
2. Bhattacharya S, Goel G, Mukherjee S, Bhaumik J, Chandy M. Epidemiology of antimicrobial resistance in an oncology center in eastern India. Infect Control Hosp Epidemiol 2015;36:864-866.

3. Roychowdhury M, Kumar J, Chakrapani A, et al. Low incidence of central venous catheter-related bloodstream infections in stem cell transplant patients in eastern India despite high community burden of multidrug-resistant pathogens. Infect Control Hosp Epidemiol 2016;37:619-620.

4. Chandy M, Das A, Bhattacharyya A, et al. Colistin-resistant Klebsiella infections among pediatric oncology and hematopoietic stem cell transplantation patients in eastern India. Infect Control Hosp Epidemiol 2018;39:118-121.

5. Goel G, Hmar L, Sarkar De M, Bhattacharya S, Chandy M. Colistinresistant Klebsiella pneumoniae: report of a cluster of 24 cases from a new oncology center in eastern India. Infect Control Hosp Epidemiol 2014;35:1076-1077.

6. Exner M, Bhattacharya S, Christiansen B, et al. Antibiotic resistance: What is so special about multidrug-resistant gram-negative bacteria? GMS Hyg Infect Control 2017;12:1-24.

7. Schilling MB, Parks C, Deeter RG. Costs and outcomes associated with hospitalized cancer patients with neutropenic complications: a retrospective study. Exp Ther Med 2011;2:859-866.

8. Jaime-Pérez JC, Fernández LT, Jiménez-Castillo RA, et al. Hospitalization rate and costs in acute lymphoblastic leukemia of childhood in a lowincome group: financial impact in Northeast Mexico. Pediatr Blood Cancer 2017;64:10.

9. Kothari A, Sagar V, Ahluwalia V, Pillai BS, Madan M. Costs associated with hospital-acquired bacteraemia in an Indian hospital: a casecontrol study. J Hosp Infect 2009;71:143-148.

10. Singh S, Kumar RK, Sundaram KR, Kanjilal B, Nair P. Improving outcomes and reducing costs by modular training in infection control in a resource-limited setting. Int J Qual Health Care 2012;24:641-648. 